Savunma Bilimleri Dergisi

The Journal of Defense Sciences

Kasim / Nov 2019, Cilt/Volume 18, Say1/Issue 2.

ISSN (Bas111) : 1303-6831 ISSN (Online): 2148-1776

\title{
Hoş Geldin Kültüründen Popülizme
}

\author{
Mustafa Nail ALKAN*
}

$\ddot{O} z$

Dünya üzerinde her yll milyonlarca insan savaşlar, iç çatışmalar, zulüm, şiddet olayları ve hak ihlalleri nedeniyle yaşadikları yerleri terk etmek zorunda kalmaktadır. Ülkelerindeki iç savaştan kaçan Suriyelilerin yaşadıkları zorluklar, Almanya halkının mültecilere yönelik bir "Hoş Geldin Kültürü” oluşturmasına ve Almanya kapılarının mültecilere açılmasına sebebiyet vermiştir. Ancak, savaşın uzaması ve mültecilerin popülist söylemlere konu edilmesi sonucunda bu Hoş Geldin Kültürü zamanla erozyona uğratılmıştır. PEGIDA ve Almanya için Alternatif Partisi gibi popülist söylemleri kendi çıkarlar için kullananlar kendilerine gün geçtikçe daha fazla sempatizan elde etmektedirler. 2017 Federal Parlamento seçim sonuçlarına göre aşırı să̆ Almanya için Alternatif Partisi Federal Parlamentoya ilk kez girerken popülist söylemlerini Parlamento çatıs altında yürütmekte ve araştırmalara göre oyunu arttırmaktadır. PEGIDA ise mitinglerine daha fazla katılımcı çekmeye ve adını Almanya dışında da duyurmaya başlamıştır. İçeride gördügü destek popülist söylemler sonrası gittikçe azalan mülteci yararına politikalar, Avrupa Birliği'ne üye ülkelerin Almanya'yı bu konuda yalnız bırakmasıyla daha da fazla tartışılır hale gelmektedir. Popülistlere karşı içeride oy kaybeden ve dışarıdan da istediği desteği bulamayan Alman Hükûmeti kendisini bir kısır döngü içerisinde bulmaktadır. Bu döngüden çıkmak için önerilen alternatiflerin hayata geçirilmesi ise popülizm ile yıpratılmış Hoş Geldin Kültürünün sonu anlamına gelecektir. Çalı̧̧manın amacı; popülist söylemlerin, uzun vadeli, geleneksel söylemlere karşı etkisini Almanya vakası üzerinden incelemektir. Bu inceleme sonucunda özellikle mülteci krizleri, yabancı düşmanlı̆̆ gibi yakın dönemdeki gelişmelerin popülist söylemlerin etkisini arttırarak aşırı săg partilerin oylarını arttırmasında etkili oldukları gözlemlenmektedir.

\footnotetext{
* Prof. Dr., Ankara Hacı Bayram Veli Üniversitesi, İ̈BF, mustafa.alkan@hbv.edu.tr Geliş Tarihi/Received : 03.09.2018 Kabul Tarihi/Accepted : 23.05.2019 Araştırma Makalesi/Research Article
} 
Anahtar Kelimeler: Hoş Geldin Kültürü, Popülizm, Mülteci Krizi, PEGIDA, Almanya İçin Alternatif.

\title{
From Welcome Culture to Populism
}

\begin{abstract}
Every year millions of people in the world are forced to leave their places because of wars, internal conflicts, persecution, violence and violations of human rights. The difficulties faced by Syrians who escaped from the civil war in their country have caused the German people to create the Welcome Culture for refugees. However, as a result of war and refugees being subject to populist rhetoric, this Welcome Culture has eroded over time. Those who use populist rhetoric such as PEGIDA and the Alternative Party for Germany for their own benefit get more supporters day by day. In 2017 Alternative for Germany entered the Federal Parliament for the first time in history, and now the Party runs populist rhetoric under the parliamentary framework and increases its vote share according to new researches. PEGIDA has begun to attract more participants to its rallies and to announce its name outside Germany. Support for politics for the benefit of refugees is becoming debatable, as a result of populist rhetoric inside and European Union countries leave Germany alone in this regard. The German Government while losing its vote share to the populists, finds zero support from the outside, is now in a vicious circle. Implementation of the suggested alternatives to get out of this cycle will mean the ending of the Welcome Culture deteriorated with populist rhetoric.
\end{abstract}

Keywords: Welcome Culture, Populism, Refugee Crisis, PEGIDA, Alternative for Germany.

\section{Giriş}

Dünya üzerinde her yıl milyonlarca insan savaşlar, iç çatışmalar, zulüm, şiddet olayları ve hak ihlalleri nedeniyle yaşadıkları yerleri terk etmek zorunda kalmaktadır. Mülteci konumuna düşen ve sığınma arayan bu kişilerin sayısı 2017 yılında 68 milyona ulaşmıştır (Arnold, 2018). 2011 yılında Suriye'de iç savaşın patlak vermesiyle bu çatışmadan kaçan ve hayatlarını kurtarma telaşına düşen 5 milyonu aşkın Suriyeli, mülteci konumuna düşmüştür. Suriyelilerin büyük bir 
bölümü ülkelerinde yaşanan çatışmaların kısa bir süre sonra biteceğini düşünerek, geri dönme ümitleriyle ilk etapta komşu ülkelere gitmişlerdir. Ülkesinden kaçmak zorunda kalan Suriyeliler başta Türkiye olmak üzere yakın coğrafyalardan Lübnan ve Ürdün'e de gitmişlerdir. Fakat Suriye'de çatışmaların uzaması nedeniyle Suriyeliler Türkiye üzerinden Balkan rotasını takip ederek Avrupa Birliği ülkelerine ve buradan özellikle Almanya'ya ulaşmışlardır. 2015 yılı sonbaharına kadar Suriyeli mülteciler sorununu tek başına yüklenmek durumunda kalan Türkiye'nin yanı sıra, Suriyelilerin Avrupa'ya yayılmasıyla birlikte, çeşitli Avrupa ülkeleri de kendilerini mülteciler sorununun içinde bulmuşlardır. Başta Almanya olmak üzere kimi Avrupa Birliği üyeleri kendi deyimleri ile 2. Dünya Savaşı sonrası yaşadıkları en büyük felaket ile karşı karşıya kalmışlardır. Almanya'ya göç eden Suriyeli mülteciler ile birlikte Almanya yeni -aslında eski- bir kavramla yeniden yüzleşmek zorunda kalmıştır: Popülizm. Özellikle siyasal ve toplumsal alanda etkili olan popülizm Alman toplumunun Suriyeli mültecilere bakış açısını şekillendiren en önemli unsur haline gelmiştir. Bu çalışmada popülizm kavramı üzerinden Almanya'da son dönemde Suriyeli mültecilere yönelik algılar ele alınmaktadir.

\section{Almanya'nın Popülizmle Yüzleşmesi}

1848 y1lında Karl Marx ve Friedrich Engels tarafindan kaleme alınan Komünist Manifestosu şu cümle ile başlamıştı: "Avrupa'da bir hayalet dolaşıyor: Komünizm hayaleti”. Marx ve Engels'in bu sözlerini günümüze uyarladığımızda şunu söyleyebiliriz ki Avrupa'da yeniden bir hayalet dolaşıyor: Popülizm hayaleti. Popülizm kavramı 19. yy'da Amerika Birleşik Devletleri'nde ortaya çıkmıştır. Kökeni Latince "populus" yani "halk" anlamına gelen kavram US People's Party'nin çiftçi ve kasaba hareketi olarak Washington elitlerine ve Doğu Asya'dan gelen göçmenlere karşı başlatılmıştır (Käppner, 2016: 36). "Dünyadaki fakir ve suçlu kişilerin Amerika'ya göç etmesini engellemek istiyoruz" söylemiyle yola çıkan hareket popülizmin başlangıcını simgelemektedir. Amerika Birleşik Devletleri'nde ortaya çıkan popülizm 1970'lerde Avrupa'ya sıçramıştır. Avrupa'da popülizmin gelişimine bağlı olarak üç evreden söz etmek mümkündür. İlk evrede Danimarka'da Fremskridtpartiet ve Norveç'te Fremskrittspartiet adlı İlerleme Partileri, İsviçre'de Schweizerische Volkspartei adlı İsviçre Halk Partisi, Fransa'da Front National adlı Ulusal Cephe ve Belçika'da Vlaams Belang adlı Flamanların 
Menfaati Partisi popülizmin belirgin örnekleri olarak karşımıza çıkmaktadır (Priester, 2012: 5-6). İkinci evre 1990'll y1llarda kendini göstermektedir. İsveç'te Ny Demokrati adlı Yeni Demokrasi Partisi, Finlandiya'da Perussuomalaiset adlı Gerçek Finliler Partisi, İtalya'da Lega Nord adlı Kuzey Ligi Partisi, Avusturya'da Freiheitliche Partei Österreichs adlı Avusturya Özgürlük Partisi, Hollanda'da De Lijst Pim Fortuyn adlı Pim Fortuyn Listesi ve Danimarka'da Dansk Folkeparti adlı Danimarka Halk Partisi popülizmin Soğuk Savaş sonrası dönemde Avrupa siyasi haritasında kendine iyiden iyiye yer bulduğunun göstergesidir (Priester, 2012: 5-6). Üçüncü evrede Batı Avrupa'da ikinci jenerasyonlar olarak adlandırılan Fransa'da Marine Le Pen'in başa geçtiği Front National (Ulusal Cephe) ile Avusturya'da Heinz Christian Strache'nin başa geçtiği Freiheitliche Partei Österreichs (Avusturya Özgürlük Partisi) popülist söylemlere devam etmiştir. Cas Mudde'nin hazırlamış olduğu 2016 tarihinde yayınlanan aşırı sağ partilerin yükselişine ilişkin raporda son dönemde bazı Avrupa ülkelerinde yapılan seçimlerde aşırı sağ partilerin oy oranlarını ciddi anlamda artırmaları "dördüncü aşırı sağ dalga" olarak tanımlanmıştır (Mudde, 2016: 3-16). Özellikle 2011 sonrası artan mülteci baskısı, Avro Krizi ertesinde halkın kemer sıkma politikaları karşısında politik kurumlara yabancılaşmasının, aşırı sağ partilerin aradaki uçurumdan istifade etmelerine ortam hazırladı ve mültecilerin kitlesel göçü karşısında halkın yaşam tarzlarının etkileneceği tezinin giderek gerçekçi hale gelmesi halkın aşırı sağa kaymasına neden oldu (Mudde, 2016: 13-15). Davis ve Deole'nin karşılaştırmalı analizleri sonucunda göçmeler ile sağ popülist partilerin yükselişi arasında bir korelasyon olduğu ve Avrupa'da aşırı sağ partilerin bu nedenle 2002-2017 yılları arasında çoğu Batı Avrupa ülkesinde aşırı sağ partilerin Cumhurbaşkanlığı, Ulusal Parlamento ve Avrupa Parlamentosu seçimlerinde düzenli olarak yükseldiğine dikkat çekilmiştir (Davis ve Deole, 2018: 10-15). Genel olarak mevcut sisteme karşı çıkan sağ popülist partilerin yükselişi, Avrupa ülkelerindeki bazı merkez partilerin popülist partilere destek veren halkı yanlarına çekebilmek amacıyla kendi söylemlerinde de sertleşmelere gitmesine neden olmaktadır. Aşırı sağ partileri özellikleri açısından tek bir şemsiye altında toplamak güçtür ancak en genel hatlarıyla yabancılara ve göçmenlere düşmanlık duyan, kurulu düzene karşı olan, popülizm üzerinde yükselen partiler olarak tanımlanabilirler. 


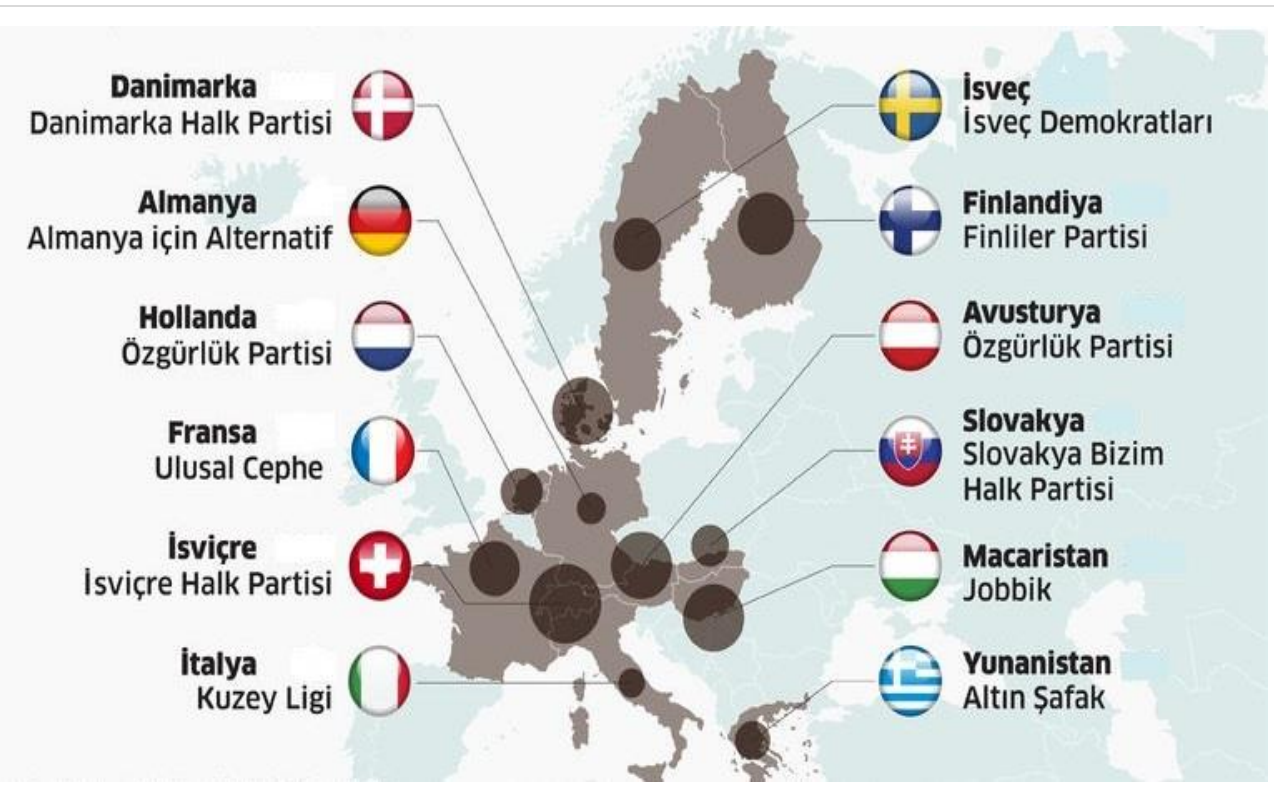

Şekil 1: Avrupa Ülkelerinde Popülist Partiler

(Kaynak: BusinessHT. (2016). İnfografik: Avrupa'da aşırı sağın yükselişi. 12 Temmuz 2018'de http://www.businessht.com.tr/guncel/haber/1265653-avrupada-asiri-saginyukselisi adresinden alınmıştır.)

Popülist parti tanımının içeriğini daha iyi anlamak adına Popülizm kavramını biraz daha açmak yerinde olacaktır. Esasen toplumsal krizlerden beslenerek ortaya çıkan popülizmin herkes tarafindan kabul edilmiş ortak bir tanımının yapılması oldukça güçtür. Geniş bir çerçevesi bulunan kavramı en genel şekliyle oportünizm (firsatçılık) şemsiyesi altında halka yakın demagoji siyasetiyle mevcut durumu dramatize ederek kitleleri etkileme yaklaşımı olarak ifade edebiliriz (Öztürk, 2012: 2). Bu çerçevede popülistler zor sorulara kolay cevaplar üreterek halk1 etkilemeye çalışmaktadır. Genellikle tabu haline gelmiş ve ihmal edilen konuları ele alırlar. Popülist dendiği zaman olumlu ve olumsuz olmak üzere iki değişik alg1 akla gelmektedir. Olumlu algıya göre popülistler halkı ve sorunlarını anlayan, bunları ifade eden ve halk ile direkt iletişim haline geçen kişidir. Olumsuz algıda ise popülistler sadece halkın duymak istediklerini söyleyen, sokaktaki insanı galeyana getiren kişiler olarak algılanmaktadır (Hartleb, 2012; 5 6). Toplumun popülizme eğiliminin artmasında en önemli nedenlerden biri kendilerinin kitle partileri tarafindan yeterince temsil edilmedikleri düşüncesidir. 
Çünkü kitle partilerinin keskin ideolojilerden uzaklaşarak gitgide birbirlerine benzedikleri görüşü mevcuttur (Decker, 2012: 10-12). Siyasi çizgilerin ortadan kalktığı, ideolojilerden yoksun ve temsili demokrasi krizlerinin var olduğu süreçlerde olgunlaşan popülizm kavramına ilişkin en temel sınıflandırma sağ ve sol popülizm şeklinde yapılmaktadır. Günümüzde oldukça etkin olan sağ popülizmde anahtar kelimeler, "dışlayıcılık ve ötekileştirme"dir. Genellikle göçmenleri, mültecileri ve Müslümanları düşman olarak gösterme eğilimi söz konusudur. Sol popülizmde ise daha çok "katılımcılık" ön plandadır. Toplumda ezilen ve dışlanmış kesimin yönetime müdahil olması amaç edinilmektedir (Grabow, 2016: 25-26). Popülizmin farklı düşünürler tarafından ve farklı açılardan ele alınarak yapılan birçok sınıflandırması mevcuttur. Bu sınıflandırmalardan en dikkat çekenlerden biri siyaset bilimci olan Pierre André Taguieff tarafindan yapilan protesto popülizmi ve kimlik popülizmi ayrımıdır (Priester, 2012: 6). Buna göre protesto popülizmi tek konu üzerine yoğunlaşan bir hareket olarak ortaya çıkmaktadır. Daha çok gücün tek bir elde yoğunlaşmasına karşı dururlar. Ayrıca hükümetler dışı hareketler olarak kendilerini tanımlamaktadırlar. Kendilerini unutulmuş olarak hisseden ve tanımlayan bu grup siyasi iktidarın kendi ihtiyaçları, duygu ve düşünceleriyle ilgilenmediğini savunurlar. Taguieff'e göre günümüzde etkin olan daha çok kimlik popülizmidir. Kimlik popülizminde kişiler kendi kültürel aidiyeti ile karşı tarafı aşağılayan bir tutum içerisindedir (Priester, 2012: 6).

Yukarıda bahsedildiği üzere popülizmin, birinci ve ikinci evresi kimi Avrupa ülkelerinde etkiliyken Almanya'da belirgin bir etkiye sahip olmamıştır. Ancak üçüncü evre uluslararası arenada yaşanan mülteci sorunu çerçevesinde Almanya'da birinci gündem maddesi haline gelmiştir.

\section{“Wilkommenskultur"}

2015 y1lı sonbaharından itibaren Suriyeli mültecilerin Avrupa Birliği ülkelerine özellikle Almanya'ya göç etmeye başlamasıyla Alman siyasetinde ve toplumunda söz konusu duruma ilişkin farklı yaklaşımlar kendini göstermiştir. Tüm dünya gibi Alman toplumu da 3 yaşındaki Suriyeli Aylan Kurdi'nin Bodrum kıyılarına vuran cansız bedeni karşısında Suriyeli mülteciler konusunda sessiz kalamamıştır. İlk başta Alman toplumu sonrasında Alman Hükûmeti Suriyelilere Almanya'nın kapılarını ve yardım ellerini açmışlardır. Alman Hükûmeti toplumla el ele vererek Wilkommenskultur (Hoş Geldin Kültürü) olarak adlandırılan yeni bir 
Alman mucizesi yaratma yolunda önemli işlere imza atmıştır (Joffe, 2015). Almanya Şansölyesi Angela Merkel'in "Biz bunu başaracağız" söylemi ve diğer taraftan Almanya'da halkın ve sivil toplum örgütlerinin gönüllü yardımları dünyaya Almanya'nın mültecilere karşı hoşgörülü ve açık bir ülke olduğu imajını vermiştir. Yapılan anketler Alman halkının \%10'unun gönüllü yardım kampanyalarına katıldıklarını göstermektedir (Engler, 2016: 6). Bir anlamda Almanya'da işlerin tersine döndüğü söylenebilir. Öyle ki eskiden Alman toplumunda Alman olmayanlara karşı bir tepki söz konusuyken bugün Alman olmayan mültecilere kucak açılmıştır. 1990'lı yıllarda aynı Almanya'da yılda ortalama 430 bin insan iltica talebinde bulunduğunda 10 Almandan 6's1 iltica hakkının sınırlandırılması gerektiğini düşünmekteydi ve gemi doldu söylemiyle daha fazla yabancıyı ülkelerinde görmek istemediklerini ifade etmekteydi (Joffe, 2015). 2015 verilerine baktığımızda, 10 Almandan 6's1 artık mültecilerden çok fazla korkmadıklarını, 10 Almandan 9'u mültecilere karşı şiddet dolu protestolardan utandıklarını ifade etmiştir. Alman toplumunun \%95'i Merkel Almanya'sının iyi insanlarının mülteciler için çaba sarfetmesini olumlu karşılamaktadır. Alman halkının \%85'i mültecilerin yasal yollarla Almanya'ya göç edebilmelerini istemektedir (Joffe, 2015). Peki, toplumdaki bu algı değişimi nasıl gerçekleşti? Özellikle sosyal medyada Suriyeli mültecilerin yüzleştiği zor şartların etkisiyle Alman toplumu bu konuda kayıtsız kalamamıştır. Ayrıca Alman toplumunun Alman kimliği anlayışında yaşanan değişimler de bu konuda etkili olmuştur. Almanya'da doğup büyümeyen -Alman kökenli olmayan- kişilerin Alman olmak için kararlı olması, bir Alman gibi yaşamak istemesi toplumun onlara yönelik olumlu algılar geliştirmesi için yeterli hale gelmiştir (Joffe, 2015). Buna karşın güncel örneklerde görüldüğü gibi oportünizm bu yaklaşımda dahi farklılaşmaların, duruma göre değişik algıların yaratılabilmesinin önünü açmaktadır.

Örneğin, 2014 Futbol Dünya Kupasının Almanya tarafindan kazanılmasında büyük pay sahibi olan Mesut Özil, Almanya için başarısız sayılabilecek olan 2018 Dünya Kupası sırasında ve sonrasinda protestolarla karşılaşmış ve bu popülist protestoların ardında yatan oportünist düşünceyi kendi sözleriyle şöyle ifade etmiştir: "Kazanınca Alman, kaybedince göçmenim" (Stanley-Becker, 2018). Popülizmin halka oynama isteği aslında olayların gerçek yapısını görememeye sebep vermekte, Özil'in de dediği gibi yüksek sesle milli marş yerine ülkesi için içten ve içinden dua edenlerin görülememesine sebebiyet 
verebilmektedir. Mesut Özil bazı duyguları içinde yaşamayı tercih ettiğini, milli marşı söylemek yerine o anları dua ederek konsantrasyon ile geçirdiğini dile getirmiştir (Herten, 2018). Popülizmin hedefi siyasetin gösterdiği hedeftir. Türklere karş1 yaratılan alg1 tüm göçmenlere, -örneğin Özil'e yönelik söylemler- tüm göçmenlere karşı oluşturulmuş söylemler olmamıştır. Bu nedenle, Alman Milli Futbol Takımındaki tüm yabancı orijinli futbolcular bu popülist söylemlerin hedefi olmamış, hatta Alman Milli Marşı'nı söylemeyen birçok diğer sporcu da bu nedenle eleştirilmemiştir. Örneğin; oynadığı dönemlerde Lukas Podolski, Jerome Boateng, Sami Khedira millî marşı söylememelerine karşın tartışma konusu ya da popülist söylemlerin hedefi olmamışlardır (Rp-Online, 2018).

2015 yılında Bertelsmann Vakfı tarafından yapılan bir anket çalışmasında Alman halkının \%98'inin Almanya'ya gelen Suriyeli mültecilerin Almanca öğrenmesini istediklerini ortaya koymuştur. Alman halkının \%97'si mültecilerin topluma daha iyi entegre olmaları için çaba sarfetmeleri gerektiğini düşünmektedir. Yine Alman toplumunun \%96's1 mültecilerin Alman Anayasası'nı kabul etmelerini, $\% 78$ 'i ise mültecilerin Alman kültürüne ayak uydurmaları gerektiğini ifade etmişlerdir (Bertelsmann Stiftung, 2015). Aynı çalışmada dikkat çeken başka bir sonuç da Almanya'da Doğu ve Batı eyaletleri arasında mültecilere yönelik algı farkını ortaya koymaktadır. Doğu eyaletlerinde (eski Doğu Almanya) devlet kurumlarının mültecilere yönelik olumlu bakış açısı \%66 oranındayken, Batı eyaletlerinde (eski Batı Almanya) bu oran \%74'lere çıkmaktadır. Aynı eyaletlerde halkın mültecilere yönelik olumlu bakış açılarına baktığımızda Doğu eyaletlerinde $\% 44$ olan oranın Batı eyaletlerinde \%63'lerde olduğu görülmektedir. $\mathrm{Bu}$ sonuçlardan anlaşılacağı üzere, Doğu eyaletlerinde yaşayan Alman halkı zamanında yabancılarla ve Müslümanlarla bir arada yaşamadığ için ve bugün de bu eyaletlerde yaşayan Müslüman oranı çok olmadığı için mültecilere karşı Batı eyaletlerinde yaşayan halkla karşılaştırıldığında daha düşük seviyelerde olumlu algilara sahiptir.

Peki, mülteciler neden Almanya'y1 tercih ediyor? Birinci neden, Almanya'nın bir refah ülkesi olması ve mültecilerin bu sebeple kendilerini daha iyi bir geleceğin ve yaşamın beklediği düşüncesinde olmalarıdır. İkinci neden, Almanya'da birçok Suriyeli yaşadığından burada var olan Suriyeli çoğunluk içerisinde mevcut akrabaları nedeniyle mülteciler Almanya'ya gelmektedir. Üçüncü neden ise Merkel'in olumlu söylemleri ve mültecilere yakın duran imajı ile 
Almanya'nın herkesi kucaklayacağı izleniminin yaratılması sonucu mültecilerin Almanya'da yaşamak istemeleridir (Engler, 2016: 6).

Almanya'nın Suriyeli mültecilere yönelik bu olumlu tutumu daha önceki göçmen akınları sırasında da gördüğümüz tutumuyla uyuşmaktadır. Zira Almanya 1950 ve 1960'lı yıllarda Akdeniz ülkelerinden ve Türkiye'den Almanya'ya göç eden işçileri de tren garlarında bando ve mızıkalarla karşılamışlardı. 2015'te de Suriyeli mülteciler böyle karşılandılar. Almanya 1960'larda ülkesine gelen işçilerin kısa bir süre çalışıp kendi ülkelerine geri döneceklerini düşünmüştü. $\mathrm{Bu}$ nedenle onları misafir işçi olarak adlandırmışlardı. Ancak sonuç Almanya'nın tahmin ettiği gibi olmadı. 2015 yılında Almanya'nın yine aynı şekilde Suriyeli mültecilerin de bir süre sonra ülkelerine döneceklerini düşündügünü söylemek yanlış olmayacaktır. Görünen o ki Suriyeli mülteciler aynı misafir işçiler gibi artık Almanya'da kalıcı hale gelmeye başlıyorlar. Almanya Federal Göçmenler ve Mülteciler Dairesi (BAMF - Bundesamt für Migration und Flüchtlinge) tarafindan açıklanan verilere göre 30 Aralık 2015 tarihi itibariyle Almanya'ya gelen mülteci sayısı 1 milyon 87 bin 478 olmuştur (Hürriyet Gazetesi, 2016). Almanya'da en çok mülteci alan eyalet 231 bin kişi ile Kuzey Ren Vestfalya eyaleti olurken bunu 159 bin ile Bavyera eyaleti ve yaklaşı 141 bin kişiyle de Baden-Württemberg eyaleti takip etmiştir. Bir önceki yıla ait resmi rakamlar incelendiğinde Almanya'nın 2015 yılında kabul ettiği mülteci sayısının 2014 yılında kabul edilenden beş kat daha fazla olduğu görülmektedir. Almanya, 2015 yılındaki 1 milyonun üzerindeki mülteci sayısıyla 1992 yılından bu yana en yüksek mülteci sayısına ulaşmıştır. 2. Dünya Savaşı'ndan sonra Almanya'ya en fazla mülteci, Bosna Savaşı nedeniyle 1992 y1lında gelmiş, bu y1l iltica başvurusu yapanların sayısı 438 bin 191 olarak belirlenmişti (Bade ve Oltmer, 2005). Almanya'nın mülteci akınına hazırlıksız yakalanması ülke içinde karşıt görüşlü hareketlerin türemesine yol açmıştır. Aşağıda göreceğimiz PEGIDA hareketi ve AfD Partisinin söylemleri neticesinde daha önce yakalanmış olan Hoş Geldin Kültürünün erozyona uğradığı görülmektedir.

\section{PEGIDA Hareketi}

Almanya'nın mültecilere yönelik açık kapı politikası ülkedeki göçmen karşıtı hareketlere hız veren en önemli unsur olmuştur. Bu hareketler içerisinde en fazla ses getiren ise Almanya merkezli kurulup daha sonra bazı Avrupa Birliği ülkelerinde de kendini gösteren PEGIDA (Patriotische Europäer gegen die 
Islamisierung des Abendlandes / Batı'nın İslamlaşmasına Karşı Yurtsever Avrupalılar) hareketidir. 20 Ekim 2014 tarihinde Dresden'de yaklaşık 400 kişilik bir grubun gösterisiyle başlayan hareket esasen 1rkçılık, yabancı düşmanlığı ve İslamofobi'yi temel alan bir söyleme sahiptir. Aralık 2014'ten itibaren dernek statüsü kazanan PEGIDA, Leipzig'te LEGIDA, Düsseldorf'ta DÜGIDA, Berlin'de BÄRGIDA, Bavyera'da BAGIDA şeklinde Almanya'nın çeşitli yerlerinde farklı adlarla oluşumunu sürdürmüştür (Tauscher, 2016: 6). PEGIDA Dresden'deki ilk gösterisinin ardından her pazartesi toplanarak katılımcı sayısını günden güne artırmıştır. 12 Ocak 2015 tarihinde Dresden'de gerçekleşen ve Paris'te yaşanan terör saldırılarından sonra yapılan İslam karşıtı mitinge toplam 25 bin kişi katılmıştır. Bu rekor sayıya rağmen mitingi organize eden yetkililer yürüyüş için sayının az olduğunu, aslında 40 bin kişinin katılması gerektiğini ifade etmişlerdir (Spiegel Online, 2015).

21 Ocak 2015 tarihine kadar hareketin sözcülük görevini yürüten Lutz Bachmann'a göre insanlar kimsenin cesaret edemediği konuları gündeme getirdiği için PEGIDA hareketini desteklemektedir (Bohmann, 2015). Kendilerini açıkça İslam karşıtı şeklinde tanımlamasalar da hareketin çoğunluğunun temelde Batı'nın İslamlaşmasına karşı korku ve endişe duyan insanlardan oluştuğu söylenebilir. Bunun yanında PEGIDA hareketini savunan insanların genellikle yabancılar, Müslümanlar ve mülteciler nedeniyle Alman kültürünün ve geleneklerinin yok olacağına dair bir düşüncede olduğu gözlemlenmektedir. PEGIDA hareketini savunanlar ülkeye göçmen ve mültecilerin gelmesinden rahatsızlık duymakta, göçmen ve mültecilere harcanan paraların ekonomik açıdan zor durumdaki Almanlar için kullanılması gerektiğini ifade etmektedir. Bu bağlamda Almanya'da mevcut siyasi partileri ve partilerin iltica ve göçmen politikalarını hedef alan PEGIDA hareketinin kurucusu Lutz Bachmann'in kendi Facebook hesab1 üzerinden mültecilere yönelik kullandığı iddia edilen küfürlü yorumlar ve hakaretler PEGIDA'nın mültecilere yönelik bakışına örnek oluşturmaktadır. Ceyhun'a göre (2015) eskiden dazlaklar, aşırı sağcı ırkçılar ve neo-nazilerin olaylı gösterileri ve ürkütücü görüntüleri yerine günümüzde PEGIDA hareketi daha şirin bir kılıfa bürünerek, bağırıp çağırmadan ve en önemlisi dazlaklar gibi Almanya'da ırkçı damgası yemeden ırkçı içerikli propagandayı başarılı bir şekilde yapmakta, bu durum da onların daha büyük kitlelere ulaşmasını ve onları yönlendirmesini kolaylaştırmaktadır (Ceyhun, 2015). Alman halkının özellikle savaştan kaçıp gelen Suriyeli mültecilere karşı başta gösterdiği anlayışlı ve hoşgörülü tavır PEGIDA 
hareketinin de etkisiyle tersine dönmeye başlamış, Alman halkı Müslüman mültecilere karşı önyargılı bir tutum içerisine girmişlerdir. PEGIDA'nın Doğu Almanya'da doğan bir hareket olmasına rağmen sonraki dönemlerde İngiltere, Avusturya, Danimarka, Norveç, Çek Cumhuriyeti ve İsveç gibi ülkelerde de kendine toplum içinde yer edinmesi sağ popülizmin Avrupa'da giderek yaygınlaştığının en bariz örnekleri olarak karşımıza çıkmaktadır.

Tablo 1: PEGIDA Hareketinin 19 Maddelik Manifestosunda Savunduğu ve Reddettiği Konular

\begin{tabular}{|c|c|}
\hline SAVUNULANLAR & REDDEDİLENLER \\
\hline $\begin{array}{l}\text { - Suç işleyen mülteciler ve göçmenler hızla } \\
\text { sınır dışı edilmelidir. } \\
\text { - Mülteciler merkezi bir yerde toplanmayıp } \\
\text { tüm Alman eyaletlerine dağıtılmalıdır. } \\
\text { - Avrupa Birliği merkezi bir daire kurmalı } \\
\text { ve mültecileri tespit edip ülkelere göre } \\
\text { dağıtmalıdır. } \\
\text { - Emniyet birimlerine daha fazla bütçe } \\
\text { ayrılmalıdır. } \\
\text { - Kadın düşmanı ve şiddet yanlısı ideolojiler } \\
\text { reddedilmelidir. } \\
\text { - Kanada, İsviçre ve Güney Afrika modeli } \\
\text { kontrollü göç politikası uygulanmalıdır. } \\
\text { - Halk önemli kararlara daha fazla dahil } \\
\text { edilmelidir. } \\
\text { - Mülteci başvuruları kısa sürede karara } \\
\text { bağlanıp sınır dışı edilecekler daha hızlı } \\
\text { sınır dışı edilmeli, edilmeyenler daha çabuk } \\
\text { Almanya’ya uyum sağlayacak kurslara } \\
\text { yönlendirilmelidir. }\end{array}$ & $\begin{array}{l}\text { - Dini veya siyasi radikalliğe izin } \\
\text { verilmemelidir. } \\
\text { - Hangi dinden olursa olsun nefret vaazı } \\
\text { verilmemelidir. } \\
\text { - Gettolar, paralel toplum yapısı, şeriat } \\
\text { polisi gibi unsurların oluşmasına izin } \\
\text { verilmemelidir. } \\
\text { - Alman Anayasası'nın terör örgütü ilan } \\
\text { ettiği örgütlere silah yardımı yapılmamalıdır. }\end{array}$ \\
\hline
\end{tabular}

Kaynak: POSITIONSPAPIER der PEGIDA. (2014). 07 Ağustos 2018 tarihinde https://www.menschen-in-dresden.de/wp-content/uploads/2014/12/pegida-positionspapier. pdf adresinden alınmıştır. 
PEGIDA'nın halktan popülizmle gördüğü desteği siyasi kazanıma çevirmeye çalışan parti ise aşırı sağ görüşlü AfD (Alternetive für DeutschlandAlmanya için Alternatif) partisi olmuştur. PEGIDA ile aynı görüşü paylaşan AfD yetkililerinden AfD Saksonya Eyalet Başkanı Urban PEGIDA ile aralarında birçok ortak noktanın olduğunu kabul etmiş̧ir (Die Zeit, 5 Mart 2018).

\section{Alternative für Deutschland (AfD)}

1960'lı yıllardan itibaren Almanya'nın Parlamento seçimlerinin sonuçlarını incelediğimizde, küçük partilerin \%5 barajını aşarak Federal Parlamento'ya giremediklerini görmekteyiz. Fakat 2013 yılında Federal Parlamento seçimlerinde Almanya için Alternatif Partisi'nin (Alternative für Deutschland- AfD) $\% 5$ barajını k1l payı ile kaçırması $(\% 4,7)$ ile Almanya'da artık bazı şeylerin değişebileceği görülmüştür (Bangel, 2013). Almanya'da son yıllarda yapılan Eyalet ve Parlamento seçimlerine bakıldığında Alman halkının büyük halk partilerinin dışında artık "diğer" diye adlandırılan partilere de oy verdiklerini görmekteyiz. 1989 y1lında Berlin Eyalet Parlamentosu'na \%7,5 oy oran1 alarak giren Cumhuriyetçiler Partisi (Republikaner) bu süreci başlatan parti olmuştur. Sonrasında bu süreç 1990'lı y1llarda kendini Hamburg Eyaleti seçimlerinde göstermiştir. 1993 ve 1997 yıllarında yapılan Hamburg Eyaleti Parlamentosu seçimlerinde diğer partilere verilen oy oranları \%16'yı geçmektedir. Bu dönemler içinde Eyalet parlamentolarına girmeyi başaran birçok parti "diğer partiler" olarak adlandırılan partiler olmuştur (Neu, 2016: 12). Büyük halk partilerinden memnun olmayan Alman halkının bir bölümü bu küçük partileri seçerek protestosunu sergilemişlerdir. Bu protestodan en kârlı çıkan parti de hiç kuşkusuz AfD partisi olmuştur. 2013 yılı Şubat ayında kurulan AfD partisi ilk aşamada Avro krizini öne çıkarmış ve Avro'nun kurtarılamaz olduğu görüşünü savunmuştur. Anti-Avro parti olarak görülen AfD 2015 yılına geldiğimizde göçmen karşıtlı̆̆ını temel alarak Alman siyasi hayatında tüm dikkatleri üzerine çekmeyi başarmıştır. 
Tablo 2: AfD’nin Eyalet Meclisi Seçimlerindeki Oy Oranları (\%)

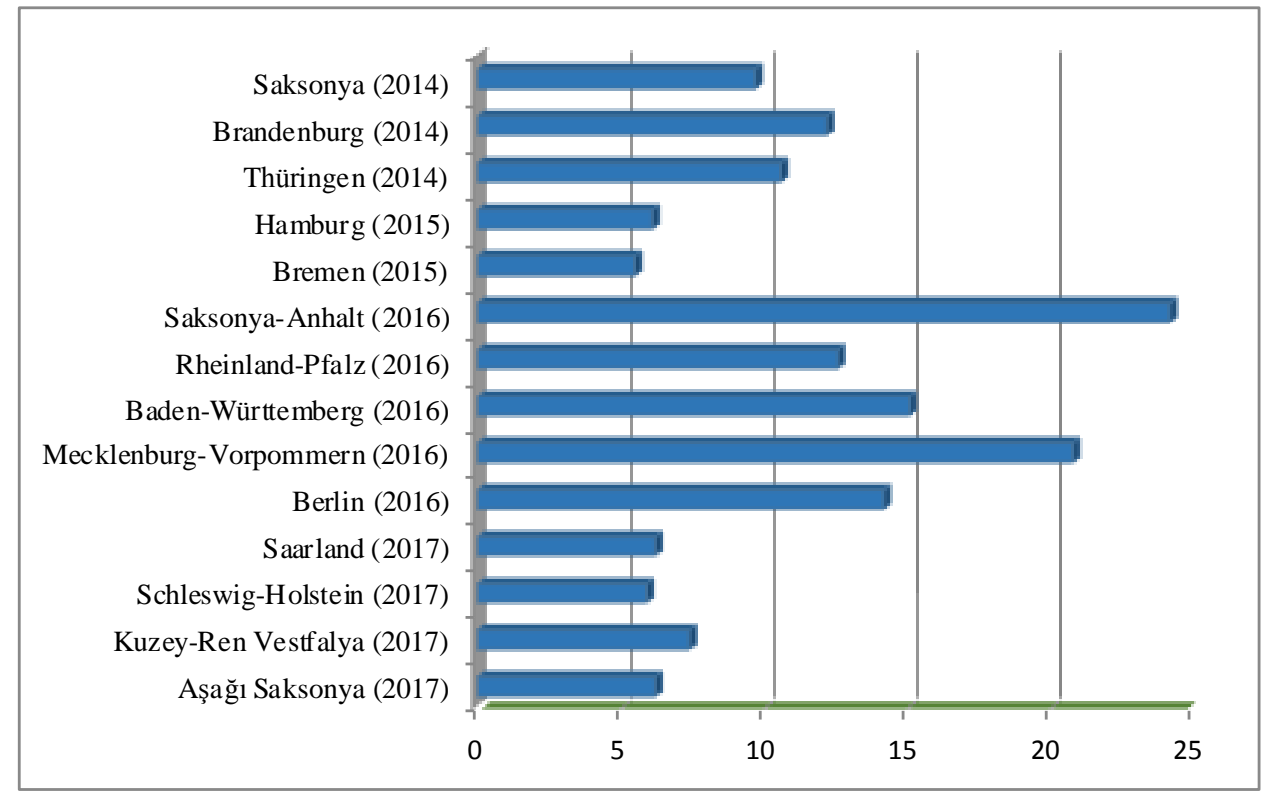

Kaynak: Hedda Nier. (2017). “ALTERNATIVE FÜR DEUTSCHLAND” AfD jetzt in 14 Landtagen vertreten. Statista. 08 Ağustos 2018 tarihinde https://de.statista.com/ infografik/5926/afd-in-den-landtagen/ adresinden alınmıştır.

AfD, yukarıdaki tabloda görüldüğ̈̈ üzere, Almanya'nın sadece birkaç bölgesinde değil tüm ülkede varlığını göstermektedir. Toplam 16 eyaletin 14'ünde bugüne kadar seçimlerde kendini gösteren AfD 2018 seçimlerinde Bavyera (14 Ekim 2018) ve Hessen (28 Ekim 2018) seçimlerine de katılacak başarı elde etmesi halinde tam anlamıyla bir kitle partisine dönüştüğünün ilanını yapacaktır. Böyle bir başarının ilan edilmesi için Almanya'da seçimlerde \%5 oranında başarı yakalamak yeterlidir.

2014 y1lında 3 Eyalet Parlamentosuna girmesi AfD’nin hızlı yükselişinin başlangıcı olarak kabul edilebilir. 2015 yılında 2, 2016 yılında 5, 2017 yılında 4 Eyalet Parlamentosunda yer alan AfD 24 Eylül 2017 tarihinde yapılan Federal Parlamento seçimlerinde \%12,6 oy oranıyla tarihi bir yükseliş yaşamıştır. 
Tablo 3: 2017 Almanya Federal Meclis Seçimleri

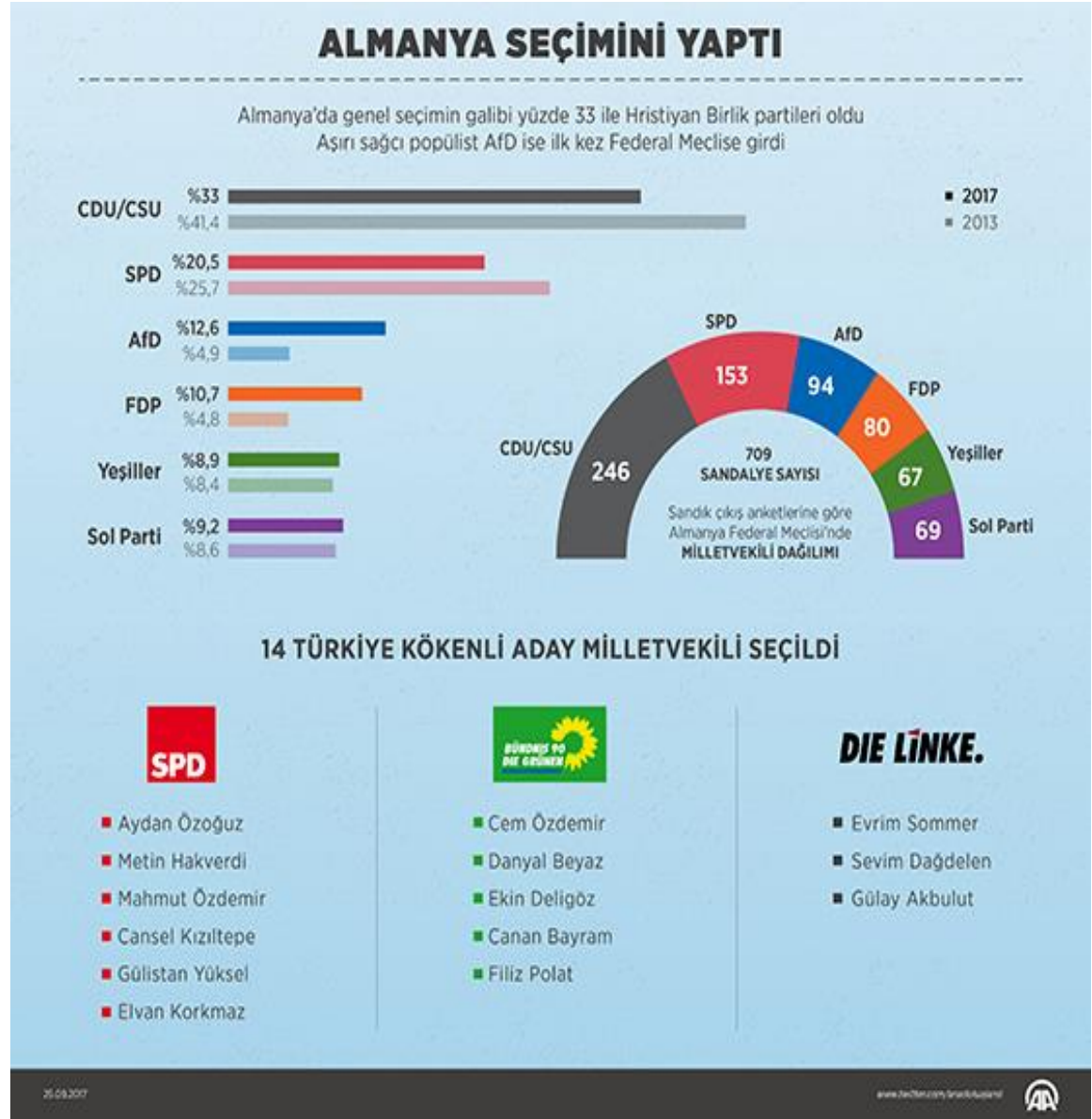

Kaynak: Erbil Başay. (2017). “Almanya Seçimini Yaptı”. Anadolu Ajansı. 21 Mayıs 2019 tarihinde https://www.aa.com.tr/tr/dunya/almanya-secimini-yapti/918536 adresinden alınmıştır.

Tablo 3'te görüldüğü üzere, Almanya Parlamentosu oy oranlarına göre AfD 3. büyük parti olmuştur (12,6 oy oranı ile) ayrıca mecliste en fazla koltuk sayısına sahip (94 koltuk- Sitzverteilung) parti olmayı da başararak aşırı sağ partiler adına ilk kez bu denli güçlü bir aşırı sağ muhalefetin parlamentoda yer almasını sağlamışlardır. Almanya seçim tarihinde, 1949 yılından bu yana ilk kez bir aşırı sağ parti Federal Parlamento'da temsil edilecek oy oranına ulaşmıştır (Deutsche Welle, 2017a). Temmuz 2018 anketlerine göre AfD'nin oy oranı \%17,5 
ila \%20 arasında gösterilmektedir ki eğer anket sonuçları gelecek seçimlere de yansıyacak olursa yükselmeye devam eden AfD, düşüşe geçen SPD (Sosyal Demokratlar) ile ikinci büyük parti olmak için kafa kafaya bir yarış içerisine girecektir (Die Welt, 2018). Bu yükselişin sebepleri arasında da mülteci krizinin siyasi popülizme malzeme edilmesinin rolü yüksektir. Aynı durum iktidar ortakları Angela Merkel'in partisi CDU/CSU ile SPD'nin mültecilerle ilgili politikalarının eleştirilmesi ve oylarının da bu eleştirilen politikalar sonucu düşmesinde etkin rol oynamaktadır.

$\mathrm{Bu}$ durum başta Almanya olmak üzere tüm Avrupa tarafından büyük bir şaşkınlıkla karşılanmıştır (Deutsche Welle, 2017b). AfD, Eylül 2017 Federal Parlamento seçimlerinde CDU'dan (Christlich Demokratische Union- Hıristiyan Demokrat Birliği) 1 milyon 70 bin, SPD'den (Sozialdemokratische Partei Deutschlands- Alman Sosyaldemokrat Partisi ) 500 bin, Linke'den (Sol Partisi) 430 bin, Grüne'den (Yeşiller Partisi) 40 bin, FDP'den (Freie Demokratische Partei- Hür Demokrat Partisi) 50 bin ve bundan önceki seçimlerde oy kullanmamış olan kitleden 1 milyon 280 bin oy almıştır (Die Welt, 2017).

AfD'nin 2014 yılından itibaren seçimlerdeki aldığı oy oranlarına baktığımızda, Almanya'da boy gösteren siyasal ve toplumsal değişimler açıça göze çarpmaktadır. Tüm Avrupa ülkelerinde olduğu gibi Almanya'da da popülizm ve aşırı sağcı partilerin yükselişi kendini göstermektedir. Almanya'da AfD ile görülen bu etkinin yansımaları 2019 Mayısında Avrupa Parlamentosu seçimlerinde ulaşmış olduğu son noktayı Avrupa kamuoyu gösterecektir. Hatta bu popülist söylemler üzerinden yükselen AfD gibi partiler, artık önleyici eylemlerle Avrupa politikasında protestocuların sığındığ 1 bir liman olmaktan öteye geçmişler ve Avrupa politikasını doğrudan etkiler hale gelmişlerdir. Bu durumda sorulması gereken soru Almanya gibi mültecilere tüm kapıları açan ülkelerde "Hoş Geldin Kültürü” gibi yaklaşımların artık sona erip ermediği sorusudur.

\section{Sonuç: Hoş Geldin Kültürünün Sonu mu?}

Bir olgunun akıllarda yer edebilmesi için o olgunun uzun süreli kullanımı ve içeriğinin değişmeden kalması beklenir. Bu anlamda Hoş Geldin Kültürünün Almanya'dan çıkarak her yerde aynı anlama gelmesi ve mülteciler için kendilerini Avrupa'da ya da kendi yurtları dışındayken de evlerinde gibi hissetmelerini sağlayacak bir anlayışın yayılıp yayılmadığı Kober'in (2017) çalışması gibi 
çalışmaların da konusu olmuştur. Bu çalışmalarda ortaya çıkan sonuç "Hoş Geldin Kültürü” tabirinin, kendisine kalıcı bir yer edinemeden gün geçtikçe literatürden silinmeye başladığıdır. Bu yok olmaya yüz tutuşun önemli sebeplerinden biri Hoş Geldin Kültürünün Almanya dışında kendine yer bulamamasıdır. Avrupa Birliği’ne üye ülkelerden, başta Macaristan, Polonya, Çekya olmak üzere, mülteciler konusunda Almanya yanında yer almamışlardır. Buna ek olarak tahmin edilen sürenin de üzerinde mülteci akınları kesilmemiş, kalıcı çözümler diğer ülkelerin de yardımlarıyla üretilememiştir. Bu nedenle Almanya üzerinde biriken sorumluluk, popülist söylemlerle vurgulanmış ve kamuoyundaki Hoş Geldin anlayışına karşı korku, saldırganlık ve ayrımcılık popülist söylemlerle körüklenerek, Deutsche Welle'nin (2018) verdiği rakamlara göre 2015'te halkın \%51'lik kısmı yeni mülteciler almaya sıcak bakarken, bu oran 2017 yılına gelindiğinde $\% 40$ oranına kadar düşmüştür.

Almanya'da Hoş Geldin Kültürünün erozyona uğraması ve Avrupa'nın sorumluluğunun Almanya'ya yüklendiği eleştirileri Angela Merkel'i de Hoş Geldin Kültürü'nden farklı yeni arayışlara yöneltmiştir. Bu çerçevede Almanya İçişleri Bakanı Horst Seehofer'in sorunu Almanya içerisinde çözme önerilerine karşı Angela Merkel sorunu Avrupa Birliği içinde çözmenin yollarını aramaktadır. Bu açıdan 01 Temmuz 2018 tarihinde Avrupa Birliği dönem başkanlığını alan Avusturya'nın sığınmacıları Avrupa toprakları yerine Kuzey Afrika'da toplayıp, dosyalarını orada inceleme isteği hatırlandığında, Merkel'in Avrupa merkezli çözüm arayışının Hoş Geldin Kültürünün sonu anlamına geleceği düşünülebilir. Zira bu öneriler Afrika ülkelerinin sıcak bakmaması ile hayata geçemeyecek görülseler de Avrupa'nın konuyu kendinden uzak, yerinde çözme çabaları mültecilere tüm kapıları kapatacaktır. Bu anlamda Emmanoulidis'in de ifade ettiği gibi (2018), halkta, başta coşkuyla karşılık bulan Hoş Geldin Kültürünün zaman içerisinde popülizm karşısında başarısız olduğu görülmektedir (Emmanoulidis, 2018).

\section{Extended Summary}

Millions of people are forced to leave their country because of wars, internal conflicts, persecution, violence and violations of rights. 5 million Syrians have left their country and seek refuge in different territories just to save their lives. In the early phases of the Civil War, Syrians chose to pass the borders to seek 
refuge for an interim period in the neighboring states like Turkey, Lebanon and Jordan. However, with the extension of the Civil War, Syrian refugees could not return to their country. The prolonging war caused Syrian refugees to spread from neighboring states to Europe. This refugee influx to Europe is called as "the refugee crisis" by the European states. This, so called, crisis revived an old phenomenon: Populism. This article takes populism into consideration to thoroughly analyze the shift in German perception on the Syrian refugees.

Populism, as a term, was born in the 19th century, in United States. It then grew up to its maturity in Europe passing through three phases. The first phase was in the 1970s, when the populist fronts were created in Denmark, Norway, Switzerland, France and Belgium. With the end of the Cold War populism's second phase exposed itself in Sweden, Finland, Italy, Austria and the Netherlands. Marine Le Pen and Heinz Christian Strache use populism in the third phase in France and Austria respectively. The latest elections proved that extreme right parties in Europe have more supporters than before and thus a new populist phase is before us. In practice populist parties use exaggerative discourse to influence people. Therefore, populist parties are opportunists that benefit from simple events with the help of exaggerative discourse. However, people might still have a positive perception of populist parties, alongside a negative perception. Populist parties attract people, who think that other parties do not represent their viewpoint on political issues. These people have a positive perception of populist parties, which seem to understand their sensitivities about issues, such as refugees that come to their country to seek asylum. Extreme right populism, in this regard, uses an exclusionary discourse depending on otherness to get more supporters. In Germany, the far right parties started using such an exclusionary discourse, particularly after the refugee crisis, to show their opposition to what Germany (and Angela Merkel's government) has achieved by opening its doors to Syrian refugees and creating a "Welcome Culture", or Wilkommenskultur as it is said in German.

The Welcome Culture is the term Germany uses to define the general support given to refugees by German people. The harsh conditions refugees faced, causing the deaths of innocent people such as the three years old Aylan Kurdi, made German people acknowledge other people's need for help. In addition to that, past experiences about immigrant workers who were not born in Germany but willing to be German helped changing German perspective on refugees coming to Germany. In 2015, 6 out of 10 German people admitted that they were no longer 
afraid of refugees, and 9 out of 10 German people stated their disappointment with the violent protests held against the refugees. According to 2015 researches $95 \%$ of the German population was positive to Merkel's efforts on supporting refugees.

Populism could not find a way if these positive images on refugees could remain so. However, the prolonging Civil War in Syria has not allowed refugees to return their home. Within time the German Welcome Culture started to become a burden no other country wants to share. Apart from the apparent external unwillingness, the internal opposition against the refugees becomes more visible with the help of PEGIDA Movement, and the far right Alternative für Deutschland (AfD) Party. PEGIDA started public opposition against refugees with a small group of 400 people, in 2014. In 2015, after the terrorist attacks in Paris, 25,000 people marched with PEGIDA. The Movement is now attracting more and more supporters from different countries and changes people's perspective on refugees by using an exaggerative discourse. Although the Movement does not call itself as an Islamophobic movement, it claims that German culture and tradition might erode because of Muslims and refugees.

The internal demand for refugees to adopt the German culture becomes a popular demand. Mesut Özil, a national football player was even blamed for not chanting the national anthem before the matches and retired from the national team because of fan protests and harsh criticisms against him. The reaction against such a successful figure, who was considered a hero in 2014 and an outsider in 2018, proves how dangerous and infectious populism can be. On the other hand, AfD showed that populism can also be very beneficial for political parties.

AfD benefited the most from the anti-refugee discourses in the German politics. In 2017 elections AfD received 12.6\% of the votes to be the first far right party in the German Parliament since 1949, when the first German elections were held. Researches show that populism's effects and influence are contagious as more and more people seem to support AfD since the last elections. According to the researches AfD may be the second largest party in the next elections, as the party seems to lead the opposition against the government and its policies toward refugees.

Those criticisms against its policies force the government to search for support not only from inside, but also from the outside. While politicians such as the Federal Minister of the Interior Horst Seehofer support policies inside Germany, Angela Merkel seeks for alternatives, which will involve European 
partners. However, such alternatives may come with a higher price than expected. European states, rather than sharing the burden, try to find ways to deal with refugees' documents outside the borders of European Union, thus they try to convince North African states to help them. Although North African states have not approved European plans yet, such plans may be the last nail in the coffin for Germany's Wilkommenskultur, as they may imply the end of open borders for refugees.

\section{Kaynakça}

\section{Makaleler}

Ceyhun, Ozan. (2015). Entellektüel Irkçılık: PEGIDA. Akademik Perspektif. http://akademikperspektif.com/2015/01/01/entellektuel-irkcilik-pegida/

Davis, Lewis ve Sumit S. Deole. (2018). Immigration and the Rise of Far-right Parties in Europe.. ifo DICE Report. vol. 15, issue 4, 10-15.

Decker, Frank. (2012). "Populismus und der Gestaltwandel des demokratischen Parteienwettbewerbs. Aus Politik und Zeitgeschichte, 5-6, 10-15.

Grabow, Karsten. (2016). Das Volk, des Volkes, dem Volk Merkmale und Trends zum Begriff des Populismus. Die Politische Meinung, No:539, Temmuz/Ağustos, 23-27.

Hartleb, Florian. (2012). Populismus als Totengräber oder mögliches Korrektiv der Demokratie?. Aus Politik und Zeitgeschichte, 5-6 , 22-29.

Käppner, Joachim. (2016). Die Werte des Westens bleiben, Interview mit dem Historiker Heinrich August Winkler. Süddeutsche Zeitung Der Grosse Jahresrückblick 36-37.

Priester, Karin. (2012). Wesensmerkmale des Populismus. Aus Politik und Zeitgeschichte, 5-6, 3-9.

Neu, Viola. (2016). Die Heimatlosigkeit des Protests. Wie sich politische Empörung in der deutschen Parteilandschaft positioniert. Die Politische Meinung, Temmuz/Ă̆ustos, No.539, 12-16.

Öztürk, Asiye. (2012). Editorial. Aus Politik und Zeitgeschichte, 5-6, 2. 


\section{İnternet Kaynakları}

Arnold, Roger. (2018). Zorla yerinden edilen insan sayıs1 2017'de 68 milyonu aşt1, mülteciler için küresel bir anlaşmanın sağlanması kritik önemde. UNHCR Türkiye. 7 Ağustos 2018 tarihinde http://www.unhcr.org/tr/19707-zorlayerinden-edilen-insan-sayisi-2017de-68-milyonu-asti-multeciler-icin-kureselbir-anlasmanin-saglanmasi-kritik-onemde.html adresinden alınmıştır.

Bade, Klaus J. ve Jochen Oltmer. (2005). Flucht und Asyl seit 1990. Bundeszentrale für politische Bildung. 9 Ağustos 2018 tarihinde https://www.bpb.de/gesellschaft/migration/dossier-migration/56443/fluchtund-asyl-seit-1990 adresinden alınmıştır.

Bangel, Christian. (2013). AfD Ergebnis Eine beinahe sehr wichtige Partei. Die Zeit. 8 Ağustos 2018 tarihinde http://www.zeit.de/politik/deutschland/201309/AFD-bundestagswahl adresinden alınmıştır.

Bohmann, Christin. (2015). Pegida spricht aus, was die Leute denken. 7 Mart 2015 tarihinde http://www.mdr.de/mdraktuell/pegida-interviewextremismusforscher100_cpage-7_zc-5f8e8344_zs-046016ee.html adresinden alınmıştır.

Deutsche Welle. (2017a). Far-right AfD enters German parliament: What it means for German politics. Deutsche Welle. 8 Ağustos 2018 tarihinde https://www.dw.com/en/far-right-afd-enters-german-parliament-what-itmeans-for-german-politics/a-40664281 adresinden alınmıştır.

Deutsche Welle. (2017b). German election: World reacts to Merkel victory, AfD rise. Deutsche Welle. 8 Ağustos 2018 tarihinde http://www.dw.com/en/german-election-world-reacts-to-merkel-victory-afdrise/a-40666611 adresinden alınmıştır.

Deutsche Welle. (2018). Kommentar: Willkommenskultur adé? Von wegen?. Deutsche Welle. 8 Ağustos 2018 tarihinde https://www.dw.com/ de/kommentar-willkommenskultur-ad\%C3\%A9-von-wegen/a-44760908 adresinden alınmıştır.

Die Welt. (2018). AfD klettert auf 17,5 Prozent und überholt die SPD. Die Welt. 8 A ğustos 2018 tarihinde https://www.welt.de/politik/deutschland/ article179083232/Insa-Umfrage-AfD-klettert-auf-17-5-Prozent-und-ueberholtdie-SPD.html adresinden alınmıştır. 
Die Zeit. (2018). Pegida und die AfD sind dieselbe Bewegung. Die Zeit. 15 May1s 2019 tarihinde https://www.zeit.de/politik/deutschland/2018-03/alternativefuer-deutschland-afd-pegida-kundgebung-joerg-urban adresinden alınmıştır.

Die Welt. (2017). Welche Parteien die meisten Stimmen an die AfD verloren. Die Welt. 9 Ağustos 2018 tarihinde https://www.welt.de/politik/deutschland/ article168989573/Welche-Parteien-die-meisten-Stimmen-an-die-AfDverloren.html adresinden alınmıştır.

Herten, David. (2018). Mesut Özil redet Klartext: Darum singe ich die Nationalhymne nicht mit. Der Westen. 8 Ağustos 2018 tarihinde https://www.derwesten.de/sport/wm2018/mesut-oezil-nationalhymneid214646165.html adresinden alınmıştır.

Hürriyet Gazetesi. (2016). "Almanya Mülteci Sayısını Açıkladı". Hürriyet Gazetesi. 16 Ağustos 2018 tarihinde http://www.hurriyet.com.tr/almanyamulteci-sayisini-acikladi-40035035 adresinden alınmıştır.

Joffe, Josef. (2015). Wilkommenskultur - Das deutsche Wunder Wieso öffnet das Land den Fremden die Tore und Herzen?. Die Zeit. 16 Ağustos 2018 tarihinde http://www.zeit.de/2015/37/willkommenskultur-deutschland-fluechtlingezeitgeist adresinden alınmıştır.

Nier, Hedda. (2017). "ALTERNATIVE FÜR DEUTSCHLAND” AfD jetzt in 14 Landtagen vertreten. Statista. 8 Ağustos 2018 tarihinde https://de.statista.com/infografik/5926/afd-in-den-landtagen/ adresinden alınmıştır.

RP-Online. (2018). Diese deutschen Nationalspieler singen bei der Hymne mit. $R p$ Online. $\quad 7$ Ağustos 2018 tarihinde https://rp-online.de/ sport/fussball/wm/dfb/wm-2014-nationalhymnen-check-diese-deutschenspieler-singen-mit_bid-19525491\#14 adresinden alınmıştır.

Spiegel Online. (2015). Pegida zieht immer mehr Menschen an. Spiegel Online. 8 Ağustos 2015 tarihinde http://www.spiegel.de/politik/deutschland/pegida-25000-teilnehmer-in-dresden-grosse-gegendemo-in-leipzig-a-1012650.html adresinden alınmıştır.

Stanley-Becker, Isaac. (2018). Mesut Özil: World Cup player says he is 'a German when we win' but 'an immigrant when we lose,' quits national team. The $\begin{array}{lllll}\text { Washington } & \text { Post. } & 7 & \text { Ağustos } & 2018 \quad \text { tarihinde }\end{array}$ https://www.washingtonpost.com/news/morning-mix/wp/2018/07/23/quittingnational-team-world-cup-player-says-he-is-a-german-when-we-win-but-an- 
immigrant-when-we-lose/?noredirect=on\&utm_term=.e4d4a4370979 adresinden alınmıştır.

\section{Raporlar}

Bertelsmann Stiftung. (2015). Willkommenskultur in Deutschland: Entwicklungen und Herausforderungen Ergebnisse einer repräsentativen Bevölkerungsumfrage in Deutschland. Bertelsmann Shiftung. 7 Ağustos 2018 tarihinde https://www.bertelsmann-stiftung.de/fileadmin/files/Projekte/ 28_Einwanderung_und_Vielfalt/Emnid_Willkommenskultur_2015.pdf adresinden alınmıştır.

Emmanoulidis, Janis A. (2018). Time to Move up a Gear: The Results of an Insufficient Summit. European Policy Centre.

Engler, Marcus. (2016). Deutschland in der Flüchtlingskrise-Hintergründe, Reationen und Herausforderungen. Heinrich Böll Stiftung. 8 Ağustos 2018 tarihinde https://pl.boell.org/sites/default/files/uploads/2016/04/ deutschland_in_der_fluchtlingskrise_engler.pdf adresinden alınmıştır.

Kober, Ulrich. (2017). Willkommenskultur im Stresstest. Bertelsmann Shiftung. 8 Ağustos $2018 \quad$ tarihinde https://www.bertelsmannstiftung.de/fileadmin/files/Projekte/28_Einwanderung_und_Vielfalt/IB_Umfra ge_Willkommenskultur_2017.pdf adresinden alınmıştır.

Mudde, Cas. (2016) The study of populist radical right parties: Towards a fourth wave. C-REX Working Paper Series No. 1, Centre for Research on Extremism, the Extreme Right, Hate Crime, and Political Violence, University of Oslo.

Tauscher, Soner. (2016). Almanya İnsan Hak ve Özgürlükleri, Ocak 2016 Raporu: Siyasal Katılım Ve Örgütlenme Hakk1. Diaspora Araştırmaları Merkezi Yayınları. 